\title{
La Révolution française, 1789-1799. Une histoire socio-politique
}

Éric Saunier

\section{Q OpenEdition \\ 12 Journals}

Édition électronique

URL : https://journals.openedition.org/ahrf/2011

DOI : 10.4000/ahrf.2011

ISSN : 1952-403X

\section{Éditeur :}

Armand Colin, Société des études robespierristes

\section{Édition imprimée}

Date de publication : 1 juin 2005

Pagination : 177-178

ISSN : 0003-4436

\section{Référence électronique}

Éric Saunier, «La Révolution française, 1789-1799. Une histoire socio-politique », Annales historiques de la Révolution française [En ligne], 340 | avril-juin 2005, mis en ligne le 20 avril 2006, consulté le 23 avril 2022. URL : http://journals.openedition.org/ahrf/2011 ; DOI : https://doi.org/10.4000/ahrf.2011

Ce document a été généré automatiquement le 23 avril 2022.

Tous droits réservés 


\title{
La Révolution française, 1789-1799. Une histoire socio-politique
}

\author{
Éric Saunier
}

\section{RÉFÉRENCE}

Jean-Clément MARTIN, La Révolution française, 1789-1799. Une histoire socio-politique, Paris, Belin, 2004, 317 p., ISBN 2-7011-3696-0, 21 e.

1 La mise au concours d'une question portant sur la période révolutionnaire créait à coup sûr, à côté de la floraison habituelle de nouveaux ouvrages destinés à enrichir la réflexion des candidats, l'opportunité de rééditer ce manuel écrit par Jean-Clément Martin au moment du Bicentenaire. Plus qu'à une simple réédition, c'est en réalité à l'écriture d'un nouveau livre à laquelle s'est livré l'auteur en raison du séisme qui a touché l'historiographie révolutionnaire depuis quinze ans. La finalité pédagogique de l'ouvrage justifie le choix d'un plan chronologique sectionné en huit chapitres donnant naissance à un récit agréable, qui accorde la part belle à l'étude des interactions entre comportements sociaux et émergence de la nouvelle culture politique, comme le suggère d'ailleurs le sous-titre choisi.

2 La capacité à rende compte de façon synthétique des apports de l'historiographie récente est sans doute la qualité principale de cette publication. Elle émerge, notamment, dans les pages que consacre l'auteur aux trois thématiques qui sont parmi les plus débattues depuis 1989: l'étude des moments de rupture dans le processus révolutionnaire, la réflexion sur la singularité des comportements caractérisant la société française de la fin du XVIIIe siècle et, surtout, l'analyse de la nature et de l'évolution de la violence révolutionnaire.

3 Concernant le premier point, dès le premier chapitre, l'auteur nous rappelle l'importance croissante qu'accorde l'historiographie à la rupture de l'automne 1789. Considérant « l'équinoxe d'octobre » comme le moment véritable qui ouvre sur une ère nouvelle en raison de l'irruption de nouveaux acteurs et de l'émergence d'une pression 
populaire, il nous invite à considérer les événements de l'été 1789 comme étant les derniers soubresauts d'une crise de vingt ans ayant touché l'une des monarchies les plus absolues et les plus figées dans les luttes entre les élites. L'intérêt manifesté pour le tournant de 1791, dès l'entame du chapitre 5 consacré à l'analyse de la radicalisation des comportements politiques, s'inscrit dans cette perspective de réflexion sur les temps de ruptures internes au processus révolutionnaire. C'est d'ailleurs là, s'agissant de l'année de la fuite de Varennes et de ses conséquences, une préoccupation que l'on retrouve dans nombre de travaux parus au moment même de cette réédition, comme le souligne la préface écrite par Michel Vovelle à l'ouvrage que Timothy Tackett vient de consacrer à cet épisode.

4 S'agissant de la complexité des tensions internes qui explique l'intensité de la crise sociale de la fin du XVIIIe siècle et des difficultés de régulation qui en découlent, JeanClément Martin nous présente surtout les facteurs explicatifs fournis par nombre d'études ayant renouvelé considérablement le regard des historiens sur les comportements et les mentalités de la noblesse et du peuple des villes. Il souligne notamment les éclairages fournis par les travaux de Jean Meyer sur les conséquences du mal-être de la noblesse d'où découle une transformation de celle-ci en aristocratie qui est d'autant plus dangereuse qu'elle émerge dans un contexte de maintien d'attitudes rébellionnaires dont Jean Nicolas a su montrer la force.

On est peu étonné, en raison des préoccupations de l'auteur, par les longs développements consacrés à la violence révolutionnaire et par l'essai d'explication des «logiques de la Terreur » à laquelle se livre Jean-Clément Martin (chapitres 6 et 7). Resituant l'arrivée de la violence révolutionnaire, comme le proposait Arthur Young, dès les événements de 1790 qui firent émerger la partition entre les partis de la Révolution et de la Contre-Révolution, c'est bien sûr à l'aune des événements de l'année 1793 qu'est étayée, à travers une présentation événementielle détaillée, une réflexion personnelle sur la violence révolutionnaire et sur la place qu'elle occupe dans le processus terroriste. Il ressort de celle-ci, comme l'a rappelé récemment Roger Dupuy, l'idée selon laquelle, pour Jean-Clément Martin, cette dernière est issue d'un désir de violence punitive du peuple élevé, du fait du poids de la guerre et de la sans-culotterie, vers un principe politique imposé à des élites politiques.

Outre l'intérêt évident que constitue la présentation de ces questionnements et des interprétations novatrices que ceux-ci suggèrent, on soulignera aussi les qualités didactiques de l'ouvrage. À côté de nombreux textes, cartes et graphiques qui jalonnent le récit, celles-ci résident surtout dans l'équilibre existant entre présentation des apports de l'historiographie française, notamment à travers la prise en compte des travaux de Pierre Serna, de Françoise Brunel, de Bernard Gainot et de Michel Biard, dans le domaine de l'histoire politique, celle de l'historiographie anglo-saxonne (on soulignera ici la place accordée aux analyses issues des recherches d'A. Forrest, de D. Sutherland et d'I. Woloch) et de travaux plus anciens (G. Lefebvre, A. Soboul) gardant tout leur pouvoir de stimulation pour la réflexion. Très bien venues sont aussi les entrées thématiques permettant au néophyte de s'initier aux questions conceptuelles délicates qui caractérisent la période révolutionnaire et les brèves notices biographiques qui facilitent la maîtrise d'une trame événementielle dont on connaît la densité.

7 On est moins convaincu, en revanche, par le choix d'une présentation chronologique sectionnée au fil des chapitres et surtout par le mode de présentation de la 
bibliographie. Plus que quelques problèmes de classification (le Que sais-je de Gérard Maintenant sur Les Jacobins figure ainsi dans "l'historiographie du genre») ou l'absence de quelques références importantes pourtant prises en considération dans les développements (on pense, dans le domaine de l'histoire religieuse, au livre classique de Timothy Tackett sur le serment constitutionnel), on regrettera la difficulté à utiliser celle-ci en raison d'un classement quelque peu sibyllin et souffrant d'un sectionnement excessif. Ces quelques regrets, imputables aux ajouts rapides qui accompagnent bien souvent les rééditions, n'invalident cependant en rien la qualité d'une synthèse dont l'intérêt et la commodité d'utilisation n'échapperont à personne. 